\title{
Aetiology, Clinical Profiles, Laboratory Profile, Outcome and Prognostic Factors of Pediatric Acute Liver Failure: Experience at a Tertiary Hospital of Bangladesh
}

\author{
*A Yasmin 1 , ASMB Karim², M Rukunuzzaman³ ${ }^{3}$ K Hossen ${ }^{4}$ L Nahar ${ }^{5}$, Z F Sonia 6
}

\begin{abstract}
Introduction: Acute liver failure is one of the common causes of death in pediatric gastroenterology and hepatology department. Outcome is different according to aetiology.

Objective: To observe the aetiology, outcome and prognostic factors of pediatric acute liver failure.

Methods: Consecutive 62 children aged 2 to 16 years of age who were diagnosed as acute liver failure from November 2015 to April 2018 were included in this study. All the clinical profiles, laboratory data and outcome were recorded in a preformed data sheet. Data were analysed by SPSS for Windows version 20.

Results: Mean age was 8.5 years. Thirty-nine (62.9\%) patients were between 5-10 years of age. Male were $53 \%$. We made a diagnosis of $39(63 \%)$ patients as Wilson disease alone, Another 3 Wilson disease acute liver failure patients had concomitent with either HAV, HEV or HSV in each one. HAV only was responsible for 17 patients and HEV for 1. One patient was Haemophagocyic lymphohistiocytosis and aetiology could not be identified in 1 patient. The overall death in study population was $48 \%$ (30). Twenty-four (57\%) of 42 acute liver failure patients due to Wilson disease had died. Five (29\%) of 17 patients due to HAV infection and 1 patient with HLH died. Ascites, high total bilirubin, high INR and etiology like Wilson disease were the worse pronostic factors for outcome of acute liver failure in children.
\end{abstract}

Conclusion: Wilson disease was the most common aetiology of acute liver failure in children in this study. Early diagnosis is essential as outcome was worse. Majority of viral etiology improved with supportive care.

Key words: ALF (acute liver failure), HE (hepatic encephalopathy), HAV (Hepatitis A virus), HBV(Hepatitis B virus), HEV(Hepatitis E virus), ALT (Alanine aminotransferase), HSV (Harpes simplex virus).

\section{Introduction}

Acute liver failure is a fatal complication of acute hepatitis. Acute liver failure is defined as - no known evidence of chronic liver disease, biochemical evidence of acute liver injury and INR $\geq 1.5$ with evidence of hepatic encephalopathy or
INR $\geq 2$ with or without hepatic encephalopathy which is not corrected after parenteral vitamin $\mathrm{K}$ therapy. ${ }^{1}$ The aetiologies of acute liver failure in children are different from adult. It also varies from one country to another and also depends on age. ${ }^{2-4}$

${ }^{1}$ Dr. Afsana Yasmin, Department of Pediatric Gastroenterology and Nutrition, BSMMU, Dhaka, Bangladesh e-mail:afsanapgn@gmail.com

${ }^{2}$ Professor ASM Bazlul Karim, Chairman, Department of Pediatric Gastroenterology and Nutrition, BSMMU, Dhaka, Bangladesh

${ }^{3}$ Dr. Md. Rukunuzzaman, Associate Professor, Department of Pediatric Gastroenterology and Nutrition, BSMMU, Dhaka, Bangladesh

${ }^{4}$ Dr. Kamal Hossen, Department of Pediatric Gastroenterology and Nutrition, BSMMU, Dhaka, Bangladesh

${ }^{5}$ Dr. Luthfun Nahar, MD Phase B Resident, Department of Pediatric Gastroenterology and Nutrition, BSMMU, Dhaka, Bangladesh

${ }^{6}$ Dr. Zannatul Ferdous Sonia, MD Phase B Resident, Department of Pediatric Gastroenterology and Nutrition, BSMMU, Dhaka, Bangladesh

*Corresponding Author

Date of submission: 10.09.2018 Date of acceptance: 24.11.2018

AKMMC J 2019; 10(1) : 56-61 
The survival of patients with acute liver failure is affected by a large number factors including age, etiology, stage of encephalopathy, presence of ascites, total bilirubin and prothrombin time. 5,6 There are a number of studies on pediatric acute liver failure in Asian countries like India and Pakistan. But there are few studies in our country, Thus this study was undertaken to see the etiologies, clinical, laboratory profiles, outcome and prognostic factors of acute liver failure in children.

\section{Materials \& Methods}

Total 64 consecutive children with acute liver failure aged 2-16 years admitted from November 2015 to April 2018 in the department of pediatric gastroenterology and nutrition were included.Two patients excluded from analysis as patients died on admission day before sending blood sample. Inclusion criteria were 1) children of 2 years to 16 years of age.2) subjects with acute liver failure due to any cause. Exclusion criteria were 1) children with liver failure had evidence of CLD.2) Acute hepatitis without liver failure. Clinical, laboratory parameters and outcome were recorded in preformed data collection sheet. Wilson disease was diagnosed according to Leipzig scoring system. Viral markers like HBsAg, Anti HBcIgM, Anti HAV IgM, Anti HEV IgM and Anti HSV IgM type $1 \& 2$ were done. Autoimmune hepatitis was diagnosed on the basis of presence of raised IgG, auto antibodies, family history of autoimmune disease. Haemophagocytic lymphohystiocytosis was diagnosed on the basis of leukocytosis, high level of ferritin level, D-Dimer, fibrinogen, triglyceride and haemophagocyte on bone marrow. Blood also sent for CBC, Bilirubin, ALT, albumin and electrolytes. At the end of study data were analysed by SPSS for Windows version 20. Descriptive statistics were used for demographic and baseline data and were presented as mean \pm standard deviation (SD), median (range), number or percentage. Chi-square test or Fisher's Exact test was used for categorical variable. Independent student t-test and Mann Whitney $U$ test were used for comparison of continuous variable. $p$ values $<0.05$ was considered as significant.

\section{Result}

Total 62 ALF children aged 2 to 16 years were analysed in this study. Mean age was 8.5 year. Age of majority (62.9\%) was between 5-10 years. Only $9(14.5 \%)$ children were below 5 years of age. Male children were $33(53 \%)$. Fourteen patients were issue of first degree consanguineous marriage. Thirteen of them were diagnosed as Wilson disease. Ascites, encephalopathy and bleeding manifestations were present in 52, 47 and 7 patients respectively. Bleeding manifestations were present in the form of hematemesis, per rectal bleeding and echyomosis. Electrolytes imbalance in the form of hypokalemia was found in 35 patients. Mean bilirubin, ALT and Prothombin time were $13.9 \mathrm{mg} / \mathrm{dL} \pm 10.4,234$. $3 \mathrm{IU} / \mathrm{L} \pm 304.1$ and $35.8 \mathrm{sec} \pm 13.9$ respectively. Severe hypoalbuminemia, below $20 \mathrm{gm} / \mathrm{L}$, was found in $37 \%$ of patients. (Table 1)

Table 1: Characteristics of studies population

\begin{tabular}{|c|c|c|}
\hline Characteristics & $\mathbf{N}$ & Percentage $(\%)$ \\
\hline Total population & 62 & 100 \\
\hline Mean age(years) & 8.5 & \\
\hline$<5$ years & 9 & 14.5 \\
\hline $5-10$ years & 39 & 62.9 \\
\hline$>10$ years & 14 & 22.6 \\
\hline Gender (Male: Female) & $33 / 29$ & \\
\hline \multicolumn{3}{|l|}{ Consanguinity } \\
\hline Total & 14 & 22.5 \\
\hline WD (n-42) & 13 & 30.9 \\
\hline Ascites & 52 & 83.9 \\
\hline Encephalopathy & 47 & 75.8 \\
\hline Bleeding manifestations & 7 & 11.2 \\
\hline Electrolytes imbalance & 35 & 56.5 \\
\hline \multicolumn{3}{|l|}{ Albumin $(\mathrm{gm} / \mathrm{L})$} \\
\hline$\geq 35$ & 11 & 17.7 \\
\hline $25-34$ & 13 & 20.9 \\
\hline $20-24$ & 15 & 24.2 \\
\hline$<20$ & 23 & 37.1 \\
\hline Bilirubin $\mathrm{mg} / \mathrm{dL}($ mean $\pm \mathrm{SD})$ & $13.9 \pm 10.4$ & \\
\hline ALT IU/L (mean \pm SD) & $234.3 \pm 304.1$ & \\
\hline PT Sec $($ mean \pm SD) & $35.8 \pm 13.9$ & \\
\hline
\end{tabular}


Table 2 shows the aetiologies of acute liver failure with frequency of death. Wilson disease alone was 39 (63\%) patients; another 3 acute liver failure patients due to WD had concomitant infection with HAV, HEV and HSV in each case. Seventeen patients had monoinfection with HAV, 1 with HEV. We made a diagnosis of Haemophagocyic lymphohistiocytosis in 1 patient and aetiology could not be identified in 1 patient. All patients came from different districts all over the country. As because, liver transplantation is not available in our country all the patients were treated with supportive care except two who went to India for liver transplantation. One due to HAV infection had improved after liver transplantation and one due to Wilson disease had died before liver transplantation. Supportive treatment were parenteral fluid, lactulose, oral or enema, antibiotic, potassium supplementation when deficit, mannitol in encephalopathy, and acyclovir in HSV infection. In Wilson disease without encephalopathy or after improving encephalopathy penicillamine was started. Among the 42 acute liver failure children due to Wilson disease alone or combined with viral cause, 24(57\%) died. Five (29\%) of 17 patients due to HAV infection died during supportive treatment and patient with HLH also died.

Table 2: Outcome according to aetiology of ALF

\begin{tabular}{lll}
\hline Aetiology of ALF & No. of children & No. of Death (\%) \\
\hline WD & 39 & $23(59)$ \\
HAV & 17 & $5(29)$ \\
HEV 1 & 0 & $(0)$ \\
HLH 1 & 1 & $(100)$ \\
WD + HSV & 1 & $0(0)$ \\
WD + HAV & 1 & $0(0)$ \\
WD + HEV & 1 & $1(100)$ \\
Non A-E infection & 1 & $0(0)$ \\
\hline
\end{tabular}

The overall death in study population was $48 \%$ (30). Table 3 compares the survivors with those who did not survive. There was no significant difference between survivors and non-survivors regarding age and gender. Fifty-two out of 62 patients had ascites (84\%). Majority 29 (56\%) of them died. Forty-six patients had encephalopathy (74\%) at the time of admission. Nine of 12 patients who had grade III and IV encephalopathy died. Sixteen of 34 patients having graded I and II encephalopathy also died. Six of 16 patients who had no encephalopathy at admission also died subsequently. There was no statistical difference between survivors and nonsurvivors. Twenty-four of 42 acute liver failures, those etiologies was Wilson disease died. But only six of 20 acute liver failure patients due to other etiology died. This difference was statistically significant ( $p$ 0.01). There were no statistical difference between survivors and non-survivors regarding leukocytosis, mean hemoglobin, ALT and albumin. Mean total bilirubin and INR were much higher in non-survival group than survivor ( $\mathrm{p}$ value $0.029,0.007$ respectively). Table 3

Table 3: Difference of clinical and laboratory parameters between survivor and non-survivor

\begin{tabular}{llll}
\hline Parameters & $\begin{array}{l}\text { Survivor } \\
\text { (n-42) }\end{array}$ & $\begin{array}{l}\text { Non survivor } \\
\text { (n-30) }\end{array}$ & p- value \\
\hline Mean age(years) & 8.8 & 8.3 & 0.55 \\
Gender(F:M) & $1: 1.1$ & $1: 1.1$ & 0.99 \\
Ascites (n-52) & 23 & 29 & 0.01 \\
no ascites (n-10) & 9 & 1 & \\
Encephalopathy & & & \\
$\quad \quad \quad$ Grade I(n-24) & 12 & 12 & \\
$\quad$ Grade II(n-10) & 6 & 4 & 0.57 \\
$\quad$ Grade III(n-7) & 3 & 4 & \\
$\quad$ Grade IV(n-5) & 0 & 5 & \\
$\begin{array}{l}\text { No encephalopathy } \\
\text { (n-16) }\end{array}$ & 10 & 6 & \\
Aetiology & & & \\
$\quad$ WD(n-42) & 16 & 24 & 0.01 \\
$\quad$ Non-WD(-20) & 14 & 6 & \\
$\begin{array}{l}\text { Leukocytosis } \\
\text { Normal leukocyte }\end{array}$ & 11 & 11 & 0.81 \\
$\begin{array}{l}\text { Hb gm/dL } \\
\text { (mean } \pm \text { sd) }\end{array}$ & $9.4 \pm 2.4$ & $8.4 \pm 2.1$ & 0.096 \\
$\begin{array}{l}\text { Bilirubin mg/dL } \\
\text { (mean } \pm \text { sd) }\end{array}$ & $11.2 \pm 10.4$ & $16.9 \pm 9.8$ & 0.029 \\
$\begin{array}{l}\text { ALT IU/L } \\
\text { (mean } \pm \text { sd) }\end{array}$ & $260.7 \pm 319.9206 .2 \pm 288.90 .485$ \\
INR (mean \pm SD) & $2.8 \pm .9$ & $3.5 \pm 1.2$ & 0.007 \\
$\begin{array}{l}\text { Albumin mg/dL } \\
\text { Nd }\end{array}$ & $21.5 \pm 5.6$ & $22.5 \pm 4.5$ & 0.505 \\
\hline
\end{tabular}




\section{Discussion}

Aetiology and outcome of acute liver failure in children differ from adult; also differ from developed countries to developing countries. In this study, most common etiology of acute liver failure was Wilson disease. It comprises 39 were alone and 3 in combinations with other viruses. Next common cause was HAV infection 17 in alone and in 1 with Wilson disease. In a previous study at same department, Mazumder et. al. showed viral hepatitis and Wilson disease were most common causes of acute liver failure in children. ${ }^{7}$ Another study done by Alam et al. in same hospital in adult acute liver failure patients, they found most common cause of fulminant liver failure was viral hepatitis. ${ }^{8}$ In India few studies were done in different states. They also found most common etiology was viral hepatitis. ${ }^{9-12}$ On the other hand, in United States, most common etiology was acetaminophen poisoning. ${ }^{13}$ Whereas in Spain, an another developed country, most common cause of acute liver failure was HBV infection irrespective of age found. ${ }^{14}$ In a large multicentre study of 384 acute liver failure children by Squires et al was found most common cause of acute liver failure was indeterminate liver failure. ${ }^{15}$ In this study, Wilson disease was the most common cause possibly due to referral bias and consanguineous marriage. Hepatitis B virus infection was not found in our series may be due to universal immunization of all children during infancy with hepatitis B vaccine by National Immunization Program.

The mean age of study population was 8.5 year which was higher than other series $(7.2$ years by Samanto et al. ${ }^{11}$, 5.8 years by Poddar et al.,${ }^{9} 5.5$ years by Bhowmick et al. ${ }^{16}$ and 5.3 years by Shah et $a l .{ }^{17}$ ). Most of the children were between $5-10$ years. Samanta et al. also found same findings. ${ }^{11}$ Gender distribution was almost equal. In our study, Ascites, encephalopathy and bleeding manifestations were found in $83.9 \%, 75.8 \%$ and $11.2 \%$ cases respectively. Podder et al. ${ }^{9}$ found ascites in $51 \%$ and bleeding in $5(7.4 \%)$ cases. Ascites was higher in frequency in our study perhaps because of large number of children were Wilson disease and hepatitis A virus infection.
Encephalopathy was found in $63 \%$ of patients by Arora et al which was almost consistent with the present study. ${ }^{12}$ In this study electrolytes imbalance in the form of hypokalemia was found in $35(56 \%)$ patients without any other electrolyte imbalance. Hypokalemia may be caused by dilution from renal wasting, volume overload or ascites and should be managed with potassium supplementation ${ }^{18}$. Hypoalbuminemia was present in 51(82.3\%) patients in the present study which was consistant with the findings of Pandit et al. (82.7\%). ${ }^{19}$ Though, high serum creatinine level was common in adult acute liver failure patients found by Shakil et al. but none in our patients. ${ }^{20}$

In the present study, we found overall mortality rate was $48 \%$. This finding was almost similar with Indian studies by Samanta et al. ${ }^{11}$ (48\%), Kaur et al. ${ }^{10}(44 \%)$. It is higher about $67 \%$ in another study by Podder et al. ${ }^{21}$ In our series death most commonly occur who are diagnosed as acute liver failure due to Wilson disease alone or in combined 24/42(57\%). Next common etiology was HAV infection $5 / 17(29.4 \%)$. On the other hand, most of the Indian studies deaths in pediatric acute liver failure patients occurred due to viral etiology9-12, 22 . Shah et. al. ${ }^{17}$ reported in a series of pediatric acute liver failure children at Karachi, Pakistan, 11 of 30 acute liver failure patients due to HAV died $(36.5 \%)$. Wilson disease presenting with encephalopathy is invariably fatal without liver transplantation. $22-23$ Majority of children in the present study had Wilson disease so fatality rate was also high.

In the present study, there was no significant difference regarding age and gender between survivor and non-survivor group. Similar findings were reported by Kaur et al. ${ }^{10}$ and Samanta et al. ${ }^{11}$. Whereas Podder et al. ${ }^{9}$. Showed younger age group had higher risk for mortality. Presence of ascites, high bilirubin and high INR were worse prognostic factors for outcome ( $\mathrm{p}$ value .01, .029. .007 respectively). Kaur et al. and Podder et al. also reported similar findings. ${ }^{9,10}$ But they also showed high grade of encephalopathy were associated with high risk of mortality. In the present study we found that not only grade III and grade IV encephalopathy at admission was associated with mortality but also 
significant number of children with low grade encephalopathy or without encephalopathy had died during the hospital course. It is better to follow up the stage of encephalopathy during hospital course. It was the limitation of the present study. There was no significant difference regarding leukocyte count, mean hemoglobin, ALT and albumin. If etiology was Wilson disease outcome would be fatal, ( $p$ value .01). O'Grady et $a l .{ }^{3}$ depicted hepatitis E as a predictor of poor outcome. Also Khuroo et al. ${ }^{24}$ documented that non A-E viral hepatitis had the highest rate of mortality. This was contradicting to our study. But Samanta et al. ${ }^{11}$ reported the highest mortality was seen in children with Wilson disease, i.e. $100 \%$, which is similar with our study.

\section{Conclusion}

Wilson disease is the most common aetiology of acute liver failure in children in the present study followed by HAV infection. Early diagnosis is essential as outcome is worse without liver transplantation in Wilson disease though majority of viral etiology are improved with supportive care. Immediate measures should be taken to establish transplantation facilities in Bangladesh to reduce the high mortality rates. Primary prevention by vaccination against HAV in young children may be useful in the prevention of ALF like HBV in Bangladesh.

\section{Conflict of interest: None.}

\section{References}

1. Bucuvalas J, Yazigi N, Squires JR. Acute liver failure in children. Clinics in liver disease. 2006 Feb; 10(1): 149-68.

2. Dhiman RK, Seth AK, Jain S, et al. Prognostic evaluation of early indicators in fulminant hepatic failure by multivariate analysis. Digestive diseases and sciences. 1998 Jun 1; 43(6): 1311-6.

3. O'Grady JG, Alexander GJ, Hayllar KM, et al. Early indicators of prognosis in fulminant hepatic failure. Gastroenterology. 1989 Aug 1; 97(2): 439-45.

4. Bernuau J, Rueff B, Benhamou JP. Fulminant and subfulminant liver failure: definitions and causes. In Seminars in liver disease 1986 May 6, (2): 97-106).
A Yasmin, ASMB Karim, M Rukunuzzam et al.

5. Bernuau J, Goudeau A, Poynard $\mathrm{T}$, et al. Multivariate analysis of prognostic factors in fulminant hepatitis B. Hepatology. $1986 \mathrm{Jul}$; 6(4): $648-51$.

6. Ostapowicz G, Lee WM. Acute hepatic failure: a Western perspective. Journal of Gastroenterology and Hepatology. 2000 May; 15(5): 480-8.

7. Mazumder MW, Karim AB, Rukunuzzaman M, et al. Aetiology and Outcome of Acute Liver Failure in Children: Experience at a Tertiary Care Hospital of Bangladesh. Mymensingh Medical Journal: MMJ. 2016 Jul; 25(3): 492-4.

8. Alam S, Azam G, Mustafa G, et al. Natural course of fulminant hepatic failure: the scenario in Bangladesh and the differences from the west. Saudi journal of gastroenterology: official journal of the Saudi Gastroenterology Association. 2009 Oct; 15(4): 229.

9. Poddar U, Thapa BR, Prasad A, et al. Natural history and risk factors in fulminant hepatic failure. Arch Dis Child. 2002; 87: 54-6

10. Kaur S, Kumar P, Kumar V, et al. Etiology and prognostic factors of acute liver failure in children. Indian Pediatrics. 2013 Jul 1; 50(7): 677-9.

11. Samanta T, Ganguly S. Aetiology, clinical profile and prognostic indicators for children with acute liver failure admitted in a teaching hospital in Kolkata. Tropical Gastroenterology. 2007; 28(3): 135.

12. Arora NK, Nanda SK, Gulati S, et al. Acute viral hepatitis types $\mathrm{E}, \mathrm{A}$, and $\mathrm{B}$ singly and in combination in acute liver failure in children in north India. Journal of Medical Virology. 1996 Mar; 48(3): 215-21.

13. Schiødt FV, Atillasoy E, Shakil AO, et al. Etiology and outcome for 295 patients with acute liver failure in the United States. Liver Transplantation and Surgery. 1999 Jan; 5(1): 29-34.

14. Escorsell À, Mas A, de la Mata M, Spanish Group for the Study of Acute Liver Failure. Acute liver failure in Spain: analysis of 267 cases. Liver transplantation. 2007 Oct; 13(10): 1389-95. 
15. Squires Jr RH, Shneider BL, Bucuvalas J, et al. Acute liver failure in children: the first 348 patients in the pediatric acute liver failure study group. The Journal of Pediatrics. 2006 May 1; 148(5): 652-8.

16. Bhowmick K, Mammen A, Moses PD, et al. Hepatitis A in pediatric acute liver failure in southern India. Indian J Gastroenterol. 2005; 24: 34.

17. Shah U, Habib Z, Kleinman RE. Liver failure attributable to hepatitis A virus infection in a developing country. Pediatrics. 2000; 105: 436-8.

18. Mazumder MW, Begum F, Karim AB. Acute Liver Failure: Management Update. Bangladesh Journal of Child Health; 41(1): 53-9.

19. Pandit A, Mathew LG, Bavdekar A, et al. Hepatotropic viruses as etiological agents of acute liver failure and related-outcomes among children in India: a retrospective hospital-based study. BMC research notes. 2015 Dec; 8(1): 381.
20. Shakil AO, Kramer D, Mazariegos GV, et al. Acute liver failure: clinical features, outcome analysis, and applicability of prognostic criteria. Liver transplantation. 2000 Mar; 6(2): 163-9.

21. Poddar B, Saigal S, Kumar A, et al. Factors associated with outcome in acute liver failure in an intensive care unit. Indian Journal of Gastroenterology. 2013 May 1; 32(3): 172-8.

22. Dhawan A. Etiology and prognosis of acute liver failure in children. Liver transplantation. 2008 Oct; 14(S2): S80-4.

23. Bellary S, Hassanein T, Van Thiel DH. 'Liver transplantation for Wilson's disease', J Hepatol, 1995; 23: 373-381

24. Khuroo MS, Kamili S. Aetiology, clinical course and outcome of sporadic acute viral hepatitis in pregnancy. Journal of Viral Hepatitis. 2003 Jan; 10(1): 61-9. 